\title{
Abdominal compartment syndrome
}

\section{Biswajit Mohapatra}

As per definition Abdominal Compartment Syndrome (ACS) is the sudden increase in the Intra-Abdominal pressure resulting in alteration in the respiratory mechanism, hemodynamic parameters, and renal as well as cerebral perfusion. ACS has tremendous relevance in the practice of surgery and the care of critically ill patients, because of its effects on multiple organ systems. Typically the patients of this syndrome are critically ill and require ventilator support.

\section{History}

The effect of the increased intra-abdominal pressure in various organ systems has been noted over the past century. Emerson first noted the cardiovascular morbidity and mortality associated with elevated intra-abdominal pressure in $1911 .^{3}$ However, the recognition of abdomen as a compartment and the concept of intra abdominal hypertension (IAH) resulting in ACS have only recently received attention. Korn and associate first used the term ACS in 1980s. ${ }^{1}$ It is only in the past decade, that the pathophysiological repercussions of the increased intra abdominal pressure (IAP) and ACS have been recognised in a wide spectrum of surgical patients and treated aggressively.

\section{Intra Abdominal Hypertension and ACS}

IAP is normally considered to be 0 or slightly sub atmospheric. After laparotomy it increases up to $10 \mathrm{~mm}$ of $\mathrm{Hg}$ and the physiological changes occur when the IAP rises up to $15 \mathrm{~mm}$ of $\mathrm{Hg}$. So intra abdominal Hypertension (IAH) is considered to be an IAP of $15 \mathrm{~mm}$ of $\mathrm{Hg}$ or greater, when the physiological derangement begins. ${ }^{5}$

ACS is organ dysfunction in the presence of elevated

\section{From:}

Department of Surgery, Vesaj Patel Hospital \& Research Center,

Rourkela - 769004, India.

Correspondence:

Dr. Biswajit Mohapatra, Room No. - 1, Vesaj Patel Hospital, H/4, Civil Township,

Rourkela - 769004, Orissa, India. E-mail: bmdoc1@yahoo.com
IAP.

\section{Grading of ACS $^{27}$ \\ Grade}

I.

II.

III.

IV.

$$
\left(1 \mathrm{~mm} \text { of } \mathrm{Hg}=1.36 \mathrm{~cm} \text { of } \mathrm{H}_{2} \mathrm{O}\right. \text { ) }
$$

10-15

16-25

26-35

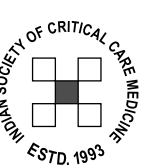

\section{.}


mal blood pressure despite the reduction in cardiac output. ${ }^{2,4}$ Thus the clinical picture is that of low cardiac output and high systemic vascular resistance in the context of high central venous and pulmonary capillary wedge pressure. ${ }^{16}$

\section{Systemic Effects on Respiratory System}

A common presentation of ACS is respiratory failure, which is characterised by high ventilatory pressure, hypoxia, and hypercapnia. Passive elevation of the diaphragm allows the transmission of high IAP into pleural cavity, reducing both static and dynamic lung compliances, and increases the peak inspiratory pressure as well as pulmonary vascular resistance. ${ }^{1} \mathrm{El}-$ evations of peak airway pressures are evident at IAP as low as $15 \mathrm{~mm}$ of $\mathrm{Hg}$. Increase in the IAP also reduces total lung capacity, functional residual capacity, and residual volume. All these factors result in ventilation-perfusion abnormality with resulting hypoxia and hypercapnia..$^{1,2,4}$

\section{Renal Effects of ACS}

Oliguria progressing to anuria and pre renal azotemia unresponsive to volume expansion is characteristic of renal dysfunction of ACS. In experimental studies carried out on euvolumic subjects, IAP of $20 \mathrm{~mm}$ of $\mathrm{Hg}$ resulted in $75 \%$ reduction in glomrular filtration rate (GFR) and a pressure of 30 or above resulted in anuria. ${ }^{1}$

The cause of renal dysfunction in ACS is multifactorial. A reduction in cardiac output leading to a reduced renal blood flow plays a minor role since optimisation of the cardiac output and filling pressure do not reverse this complication. ${ }^{1,8}$

The renal derangements involve reduced absolute and proportional renal blood flow, increased renal vascular resistance with changes in intra regional blood flow, reduced glomerular filtration, and increased sodium and water retention. These effects have been attributed to direct compression of renal veins, cortical arterioles, and renal parenchyma. Renal derangement may also be due to corticomedullary shunting of renal plasma flow, reducing effective renal plasma flow. Increase in the circulating level of $\mathrm{ADH}$, renin, and aldosterone due to changes in renal and systemic hemodynamics, further increases the renal vascular resistance and produces sodium and water retention. ${ }^{1,4,11}$

\section{Effects of ACS on Splanchnic Circulation}

The effect of IAP is associated with reduction in hepatic, mesenteric, and splanchnic blood flow. Diabel et al found that while the mesenteric and intestinal mucosal blood flow reduction occurs at a IAP of $20 \mathrm{~mm}$ of $\mathrm{Hg}$, hepatic and portal flow become compromised at a IAP of $10 \mathrm{~mm}$ of $\mathrm{Hg} \cdot{ }^{21}$ Recent evidences suggest that portal venous pressure raises parallel with the IAP. Hepatic artery and portal venous flow reduces by $40 \%$ and $30 \%$ respectively at an IAP $>15 \mathrm{~mm}$ of $\mathrm{Hg} .{ }^{1}$

Increased IAP results in a decrease in mesenteric blood flow to $63 \%$ of base line despite maintaing normal mean arterial blood pressure..$^{22}$ Reduced superior mesenteric arterial blood flow leads to impaired mucosal blood flow and mucosal oxygen delivery. This further leads to anaerobic cell metabolism, lactic acidosis, free radicals generation, and translocation of bacteria from the gut, which contributes to later septic complications and multiorgan dysfunction syndrome. ${ }^{23}$ Small bowel ischemia and elevated portal venous pressure causes visceral oedema, which further increases the volume of the abdominal contents in the peritoneal cavity and raises the IAP to an alarming level.

\section{Effects of ACS on Abdominal Wall}

Increased IAP has been shown to reduce the abdominal wall blood flow by the direct compressive effect of $\mathrm{IAH}$, leading to local ischemia and oedema. Blood flow to the rectus is reduced by $60 \%$ at an IAP of $10 \mathrm{~mm}$ of $\mathrm{Hg}$ or more. ${ }^{1}$ As collagen deposits and resistance to infection are directly proportional to tissue perfusion and oxygenation, elevated IAP adversely affects the wound healing.

\section{Intracranial Effects of IAP}

The elevated IAP increases the intra cranial pressure and reduces the cerebral perfusion pressure secondary to elevated intrathoracic pressure and elevated central venous pressure with impaired cerebral venous outflow. ${ }^{1,4}$

\section{Systemic Reperfusion Injury}

Rapid decompression of the abdomen results in acute hypovolemia as a result of the decompression of the mesenteric vascular bed and release of lactic acid into the blood stream. This is also a sequel of abrupt drop in central filling pressure and systemic vascular resistance. Supraventricular arrhythmias and episodes of asystole 
have also been reported. The factor responsible for these adverse events is the rapid washout and systemic circulation of lactic acids, potassium, and other by products of anaerobic metabolism, from the reperfused viscera and lower extremities. ${ }^{1,8}$

Gut ischemia promotes regional production of inflammatory mediators, expression of cell adhesion molecules on endothelial and immune cell surface and increases the procoagulatory property of vascular endothelial surface. During reperfusion, gut injury may be amplified by increased production of free oxygen radicals and exhaustion of endogenous antioxidant defence mechanism. Translocation of bacteria and toxins through the leaky gut mucosa again amplify or perpetuate systemic inflammation, leading to multiple organ dysfunction syndrome and death in critically ill patients. ${ }^{23}$

\section{Types of ACS 5,10}

1. PRIMARY ACS is essentially organ dysfunction and $\mathrm{IAH}$ in the presence of direct injury to the abdominal contents. The examples are trauma, peritonitis, ileus, and haemorrhage etc.

2. SECONDARY ACS consists of elevated pressure and organ dysfunction caused by third space oedema and resuscitation. The examples are resuscitation of haemorrhagic shock patients, burns etc.

3. RECURRENT ACS in which the patient has recovered from the ACS once but because of secondary insults the cycle begins again. This verity is associated with very high mortality rate.

\section{Etiology}

ACS develops as a result of an acute and marked increase in IAP due to the following cause

1. Spontaneous - Peritonitis, intra abdominal abscess, Intestinal obstructions,

Ruptured abdominal aortic aneurysm,

Tension pneumoperitoneum,

Acute pancreatitis,

Acute mesenteric ischemia.

2. Postoperative - Peritonitis, abscess, ileus, Intra peritoneal haemorrhage.

3. Post- traumatic - Intra-, retro-peritoneal bleeding,

Post-resuscitation visceral oedema.
4. latrogenic -

Laparoscopic procedure, abdominal packing,

Abdominal closure under tension.

\section{Diagnosis}

The diagnosis of ACS depends on a very high degree of suspicious and recognition of the patients at risk, identification of clinical syndrome and lastly measurement of IAP. C. T. scan of abdomen can help to establish the diagnosis in few cases of ACS.

\section{Clinical Parameters}

1. Distended abdomen

2. $\mathrm{IAP}>20 \mathrm{~mm}$ of $\mathrm{Hg}$

3. Elevated peak airway pressure

4. Massive I.V. fluids requirements

5. Oliguria to anuria not responding to volume repletion

6. Decreased cardiac output

7. Hypoxemia refractory to increase $\mathrm{FIO} 2$ and PEEP

8. Hypercarbia

9. Hypercapnia

10. Wide pulse pressure

11. Acidosis

\section{Patients at Risk}

1. Abdominal trauma

2. Haemorrhage

3. Peritonitis

4. Emergency aortic surgery

5. Intra abdominal packing

6. Forced abdominal closure, etc.

\section{Measurement of IAP}

IAP can be measured by direct or indirect methods. Though the direct methods are quite accurate over all ranges of IAP, it is impractical and not feasible for routine practice. Indirect pressure measurement is done through Inferior Vena cava, gastric, rectal and Urinary Bladder. However, the simplest and the method of choice is the Urinary bladder pressure measurement (UBP). However the measurement may be inaccurate in cases of neurogenic bladder, small contracted bladder and bladder trauma cases. ${ }^{1}$

\section{How to Measure UBP}

The most widely used method is transurethral measurement of UBP using a Foley's catheter. Kron et al first 
described this technique. ${ }^{4}$ The bladder is drained and then it is filled with 50 to $100 \mathrm{ml}$ of normal saline. This saline in the bladder acts as a passive diaphragm for pressure transmission. The drainage tube is clamped beyond the aspiration port and a 16-gauge needle is inserted into the port. The tubing is then attached to a water manometer or a pressure transducer, using the symphysis pubis as the zero reference point.

Sedrak et al had recently come out with a simple fluid column manometry system via the Foley catheter to measure the intra abdominal pressure..$^{20}$ In this method the drainage tubing is first marked with a silk tape along its length. The Foleys catheter is marked as ' 0 ', few $\mathrm{mm}$ proximal to the $\mathrm{Y}$-junction, which serves as the zero reference point when it is at the level of symphysis pubis. The drainage tubing is marked at an increment of $1 \mathrm{~cm}$ on the tape, starting from the mark on the Foley's catheter as ' 0 '. Next introduce 50 to $100 \mathrm{ml}$ of sterile saline into the bladder. After reconnecting the Foley's catheter to the drainage tubing, the zero reference point is kept at the level of pubic symphysis and the drainage tubing is raised vertically. The transition from horizontal to vertical is at ' 0 ' mark and should not be too abrupt. The distance the sterile saline raises vertically in the tubing is the IAP in $\mathrm{cm}$ of $\mathrm{H}_{2} \mathrm{O}$. By this method the pressure can be measured hourly and is simple to do.

\section{T. Scan Findings ${ }^{17}$}

1. Tense infiltration of the retro peritoneum out of proportion to peritoneal disease.

2. Extrinsic compression of the inferior vena cava by retroperitoneal haemorrhage or exudates.

3. Massive abdominal distension with an increased ratio of AP to transverse abdominal diameter.

4. Direct renal compression or displacement.

5. Bowel wall thickening with enhancement.

6. Bilateral inguinal herniation.

\section{Management of ACS}

The emerging hypothesis is that it is the physiological derangement and not the severity of the initial peritoneal infection that is the main determinant of outcome and therefore all efforts should be directed to bring the physiology to the normal status.

As the patients of ACS are critically ill, many of them required the ventilatory support. The main reason be- hind it is the acute rise in abdominal pressure to a pathological level. Abdominal distension due to raised IAP markedly alters respiratory system mechanics primarily by "stiffening" the abdominal part of the chest wall and secondarily by restricting lung expansion, thus shifting the lung Pressure-Volume curve, resulting in high ventilatory pressure, hypoxia and hypercapnia. Reducing the pressure by decompression and maintaining it by keeping the abdomen open with temporary abdominal closure can reduce the requirement of ventilator and the mortality rate to a greater extent.

As direct measurement of intra abdominal pressure is not a practical method at all, measurements by the indirect methods are used as the method of choice. Mostly the intra vesicle pressure is considered as the gold standard for the management of ACS. It is not the intra vesicle pressure alone dictate the term for decompression. It is the raised pressure with physiological derangements and organ dysfunctions which needs consideration.

Abdominal decompression is the only definitive management of ACS. Optimally, decompression involves either reopening a laparotomy incision or, in patients without recent laparotomy, opening of the abdomen through a midline incision. Even decompression in the intensive care unit may be indicated in few cases, where the hemodynamic or pulmonary instability precludes safe transport to the operating room. ${ }^{1}$

Few precautions should be taken prior to decompression, to prevent the systemic reperfusion injury. Rapid infusion of few liters of crystalloids within few minutes of post decompression is required to restore hemodynamic stability. Immediately prior to decompression, a 'decompression cocktail' consisting of one liter of normal saline, two ampoules of $\mathrm{NaHCO}_{3}$ and $50 \mathrm{mg}$ of mannitol is administered. This augments the pre-load, neutralises the acute release of acids from mesenteric circulation, and stimulates the renal diuresis. $^{3}$

The nature of decompressive laparotomy depends on the clinical situation. The laparotomy findings, previous operation, etiology of $\mathrm{IAH}$, previous damage control procedures and the means of closure, affect it. According to the individual pathology different options are being 
considered for the management of the abdominal wound after the emergency laparotomy.

Meldrum et al (1997) recommended different therapeutical approaches according to the level of IAP: 6

1. Grade I - (10 - $15 \mathrm{~cm}$ of $\mathrm{H} 2 \mathrm{O})$ - To maintain normovolumia.

2. Grade II - (16 - $25 \mathrm{~cm}$ of H20) - Hypervolemic resuscitation.

3. Grade III - (26 - $35 \mathrm{~cm}$ of $\mathrm{H} 2 \mathrm{O})$-decompression.

4. Grade IV - (>35 cm of H2 O) -decompression and re exploration.

He recommended prompt decompression in the presence of an IAP greater then $20 \mathrm{~mm}$ of $\mathrm{Hg}\left(26 \mathrm{~cm}\right.$ of $\mathrm{H}_{2} \mathrm{O}$ approx.) and any significance physiological abnormalities such as elevated peak airway pressure or oliguria.

In severe abdominal trauma and inflammation, which requires massive fluid replacement, development of ACS can be foreseen due to massive bowel, abdominal wall, retroperitoneal, and solid organ oedema. Tight abdominal closure in these circumstances can worsen the tissue injury and can result in fatal outcome. A good rule of thumb is that if, when looking at the abdomen horizontally, the guts can be seen above the level of the wound, the abdomen should be left open and temporary abdominal closure (TAC) utilized. ${ }^{7}$ It is better to anticipate the development of abdominal compartment syndrome and use an alternate wound closure technique to prevent its occurrence.

There are basically three different types of advanced treatment techniques for the management of ACS.

1. Laparostomies

2. On demand re-laparotomies

3. Staged abdominal repair (STAR)

Laparostomies or open abdominostomy is generally defined as a laparotomy without re-approximation and suturing of the abdominal fascia. Though this method has got several advantages, the complication rate is very high. The complications are,

1. Massive fluid losses

2. Evisceration of intra-abdominal contents

3. Contamination by exogenous organisms

4. Fistula formation

5. Post-op abdominal wall hernias

\section{Small bowel obstruction}

On-Demand Re-Laparotomies is dictated by the patient's clinical condition and is the technique by which most of our patients are managed, and has a mortality of 30 to $76 \% .^{26}$

Stage Abdominal Repair (STAR) is a technique of serial operation, planned either before or during the first index operation, performed every 24 to 48 hours, with temporary closure of the abdomen, and culminating in a final aponeurosis-to-aponeurosis abdominal closure. During the course of treatment a controlled tension is exerted on the margins, avoiding an artificially caused Abdominal Compartment Syndrome due to intra abdominal inflammation, oedema, and ileus. For the prevention and therapy of manifested Abdominal Compartment Syndrome (ACS), staged abdominal repair (STAR) operation is gaining more popularity, because of its lower complication rate. Virtually all materials which are non reactive to the body tissue, can be used for temporary closure of abdomen.

According to Wittmann and colleagues STAR appears to reduce mortality by $50 \%$ over the standard operations and patients operated on at $24 \mathrm{hrs}$ intervals seems to do better then those whose staged operations are performed at a wider interval. ${ }^{12}$ STAR facilitates easy second look, stabilisation of the patient's general condition, decompresses the abdomen, and helps in organ recompensation.

Currently, no prospective studies showing which is the best method or material have been published. Superiority of one over the other material has not been established. The materials advocated are Mesh (absorbable, non absorbable), Zipper, Adhesive sheets, Plastic bag (Bogota bag), and Velcro analog.

Because of a very high rate of fistula formation and bowel erosions, use of mesh alone is discouraged. Incorporating an adhesive foil (Op-Site) on the visceral side of the mesh reduces the incidence of this complication.

The use of a non-adhesive plastic foil derived from irrigation bag (Bogota Bag) is quite satisfactory. These are sutured away from the skin margins, leaving the 
fascial margin untouched, for future repair. The advantage of Bogota bag is that it is cheap and transparent, so that abdominal contents can be viewed through the plastic. This is particularly useful in cases with ongoing ischemia and necrosis of bowel and haemorrhage.

An alternative method is the 'Vacuum-pack' technique. Here the 3 litre genitourinary irrigation bag is opened and placed into the abdomen to protect the gut contents, under the sheath. Two large calibre suction drains are placed over this, and a large adherent steridrape placed over the whole abdomen. The suction catheters are connected to high-displacement suction to provide control of fluid losses and create the 'vacuum-pack' effect. This minimizes the 'Wet bed 'problem.'

An open abdominal wound is a great challenge to a surgeon in the postoperative management, due to (i) massive fluid loss, (ii) heat dissemination (iii) risk of infections. Frequent assessment and care of the wound and replacement of the lost fluids and electrolytes are mandatory. Strict aseptic technique is required for wound care.

\section{Conclusion}

The abdominal compartment syndrome is a well-recognised disease entity related to acutely increased abdominal pressure. The mortality rate of ACS is very high. Recognizing patients at risk, monitoring the abdominal pressure frequently, and early initiation of treatment could reduce the mortality to a significant level.

\section{References}

1. Nathens AB, Brenneman FD, Boulanger BR. The Abdominal Compartment Syndrome. Can J Surg 1997;4:254.

2. Sieh KM, Chu KM, Wong J. Intra abdominal hypertension, and Abdominal Compartment Syndrome. Langenbeck's archives of surgery $2001 ; 386: 53-61$.

3. Cheatham ML, Abdominal compartment syndrome, case and lecture, www.orlandoregional .org/for_physicians/med_ed/surgical

4. Holzheimer RG, Mannick JA, Abdominal compartment syndrome. Surgical Treatment: - Evidence based and problem oriented. Chapter XVI, http://www.freebooks4doctors.com/fb/ spec18.htm\#surge

5. Rotondo MF, Cheatham ML, Moore FA, Reilly PM. Abdominal Compartment Syndrome-Symposium; Cotemporary Surgery 2003:59:260-70
6. Meldrum DR, Moore FA, Moore EE, Franciose RJ, Sauaia A, Burch JM. Prospective characterization and selective management of the abdominal compartment syndrome. Am J Surg 1997;174:667-72

7. www.trauma.org/traumabank html. Damage Control Surgery; Abdominal Compartment Syndrome.

8. Reis R, Labas P, Vician M, Ziak M. Abdominal compartment Syndrome. Bratisl Lek Listy 2003;104:32-5.

9. Balogh Z, Mckinley BA, Holcomb JB, Miller CC, Cocanour CS, Koz RA, et al. Both primary and secomndary Abdominal syndrome can be predicted early and are harbingers of multiple organ failure. J Trauma 2003:54:848-59.

10. Majchrzak C, Abdominal Compartment syndrome: A case review. J of Perianesthesia Nursing 2003;17:413-9.

11. Tan IKS, Kua JSW. Abdominal compartment syndrome and acute anuria. Nephrology Dialysis Transplantation 1998;13:2651-3.

12. Wittmann $\mathrm{DH}$, Aprahamian $\mathrm{C}$, Bergstein JM, et al. A burr-like device to facilitate temporary abdominal closure in planned multiple laparotomies. Eur J Surg 1993;159:75-9.

13. Schachtrupp A, Fackeldey V, Klinge U, Hoer J, Tittel A, Toens C, et al. Temporary Closure of Abdominal wall (laparostomy). Hernia 2002;6:155-62.

14. Lonsoff JE, Richman BW, Jones JW. Temporary Abdominal Coverage, and reclosure of the Abdomen: Frequently asked questions. J Am Coll Surg 2002;195:105-15.

15. Schachtrupp A, Reckord U, Klinge U, Hoer J, Toens C Schumpelick V. Intra abdominal pressure: A reliable criterion for laparostomy closure? Hernia 2002;6:102-7.

16. Barnes GE, Laine GA, Giam PY, Smith EE, Granger HJ. Cardiovascular responses to elevation of intra-abdominal hydrostatic pressure. Am J Physiol 1985;248:208-13.

17. Pickhardt PJ, Shimony JS, Buchman TG, Fisher AJ. The abdominal compartment syndrome: CT findings. Am J Roentgenol 2000;175:267-8.

18. Cleva RD, Silva FP, Zilberstein B, Machado DJB. Acute renal failure due to Abdominal Compartment Syndrome: Report on four cases and literature review. Rev Hosp Clin 2001:56:123-30. http://www.scielo.br/scielo.php?script=sci_arttext\&pid=S0041. $87812001000400006 \&$ lng=en\&nrm=iso

19. Liolios A. Expert Emphasize the consequences of high intra abdominal pressure in critically ill patients. http:// www.medscape.com/viewarticle/455751

20. Sedrak M, Major K, Wilson M. Simple fluid column manometry to monitor for the development of Abdominal compartment Syndrome. Contemporary Surgery 2002;56:6.

21. Diable LN, Dulchavsky SA, Brown WJ. Splanchnic ischemia and bacterial translocation in the abdominal compartment syndrome. J Trauma 1997:43:852-5. 
22. Waker J, Criddle LM. Pathophysiology and management of abdominal compartment syndrome. Am J Crit Care 2003;12:367-71.

23. Schwarj B, Salak N, Hofstotter H, Pajik W, Kontzer H, Mayr A. Intestinal ischemia reperfusion syndrone: Pathophysiology, clinical significance, therapy. Wien Klin Wochenschr 1999;111:539-48.

24. Baker DD. Abdominal compartment syndrome. Crit Care
1999;3:R103-4.

25. http://www.openabdomen.org.

26. Yalamarthi S. A review of laparostomy, methods available. http:/ /www.edu.rcsed.ac.uk/lectures/lt18_1.htm.

27. Bruch JM, Moore EE, Moore FA, Franciose R. The Abdominal Compartment Syndrome. Surg Clin North Am 1996;76:833-42. 